\title{
Cellulose nanofibers as substrate for flexible and biodegradable moisture sensors
}

\author{
Almudena Rivadeneyra ${ }^{*}, 1$, Antonio Marín-Sánchez ${ }^{2}$, Bernd Wicklein ${ }^{3}$, José F. Salmerón ${ }^{4}$, \\ Encarnación Castillo ${ }^{1}$, Marco Bobinger ${ }^{4}$ and Alfonso Salinas-Castillo ${ }^{2}$
}

${ }^{1}$ Department of Electronics and Computer Technology, University of Granada, 18071, Granada (Spain)

${ }^{2}$ Department of Analytical Chemistry, University of Granada, 18071, Granada (Spain)

${ }^{3}$ Instituto de Ciencia de Materiales de Madrid (ICMM), Consejo Superior de Investigaciones Científicas (CSIC), 28049, Madrid (Spain)

${ }^{4}$ Institute for Nanoelectronics, Technical University of Munich, 80333, Munich (Germany)

*Corresponding author: arivadeneyra@ugr.es

Abstract - Flexible and biodegradable electronics is attracting the interest of the Internet of Things industry. The necessity of sustainable development and environmental friendly electronic devices forces manufactures to reduce electronic wastes and toxic residues. Cellulose nanofibers are biodegradable and flexible materials suitable to build self supported film electronics and are seeing first employment in sensor fabrication. In this work, cellulose nanofibers based moisture sensors are reported, which are characterized at different working frequencies showing a good dependence with relative humidity (RH). A transparent and fully biodegradable moisture sensor was fabricated based on a PEDOT:PSS electrode showing a wide operation range from $20 \%$ to $85 \% \mathrm{RH}$, where $\mathrm{CNF}$ film acts as the sensing layer without any additional processing. In order to manufacture the sensor, a one-step fabrication method based on screen-printing was applied, which offers a more reproducible and cost-effective solution than others techniques. In addition, this method offers the possibility to easily redesign the sensor saving time and money. Thus, our work presents a versatile, transparent, self-supported film moisture sensor with a promising adaptability to the green-electronics industry.

Keywords: Additive manufacturing; Carbon fibres; Electrical properties; Environmental Degradation; Sensing 


\section{Introduction}

Humidity sensors have gained much attention as a basic device for Internet of Things (IoT) solutions [1, 2]. Environmental control systems for industrial and manufacturing processes [3], smart food packaging [1], and monitoring in agriculture [4] are some of the main applications of this type of sensors. Also, the use of humidity sensors in medical applications have reached certain relevance to monitor respiration $[5,6]$. These applications require flexible and selfsupported film humidity sensor technologies in order to improve the device portability and compatibility to meet the desired specifications.

A good performance of flexible humidity sensors in a wide range of humidity and temperature values is one of the main goals for such sensors. Reducing device dimensions and decreasing the cost of fabrication are some of the advantages of self-supported film and flexible sensors technologies. Besides, controlling stability of the surrounding atmosphere is one of the main issues to deal with in order to ensure the reproducibility and accuracy during the fabrication process [7].

On the another hand, reducing electronics wastes and toxic residues that can be filtered into the environment and contaminate water and food is becoming an eminent topic in the scientific community [8]. In order to ensure a sustainable development of electronic technologies, green fabrication processes and biodegradable materials ought to be employed. For this reason, materials like biopolymers [9], and specifically cellulose, [10-15] are currently attracting much attention in literature as a popular material.

In particular, cellulose nanofibers (CNFs) are biodegradable [16] and present a large amount of hydroxyl groups in their molecular chains $[17,18]$. Water molecules easily interact via hydrogen bonding with these $\mathrm{OH}$ groups and in consequence, vary the electrical permittivity of the material. This mechanism renders CNF a promising moisture sensitive material. In addition, the fabrication technique used to extract CNF is a widely accessible procedure. The transparent nature of CNF makes this material suitable to also develop transparent flexible sensors. 
Transparent devices are interesting as they can be easily adapted to and implemented in design requirements for pervasive, invisible technologies which is a fundamental idea of ubiquitous computing and IoT.

Transparent humidity sensors based on cellulose substrates have been reported in literature before [19-24]. A flexible cellulose nanofiber/carbon nanotube humidity sensor is reported by Zhu et al. with a humidity range between $11-95 \% \mathrm{RH}$ and a sensitivity of $69 \%(\Delta \mathrm{I} / \mathrm{I} 0)$ [19]. However, the composite film employed in this work is not transparent unlike the humidity sensor reported by Wang et al. which presents this quality with a humidity range from $11 \%$ up to $97 \%$ and a sensitivity of -0.05 (Z/\%RH) [20]. Regarding the fabrication techniques, Syrový et al. reports a CNF based humidity sensor manufactured using screen printing and this sensor presents a humidity range of $11-90 \% \mathrm{RH}$ with a sensitivity of $-0.11(\mathrm{Z} / \% \mathrm{RH})$ [21].

In this context, developing biodegradable, self-supported film sensors is the main objective of this paper. In addition, invisible electronics could be also relevant to future scenarios where humans may interact with technology without perceiving it. Besides, transparent devices do not affect the aesthetic appearance and usability of the surface where this electronics is employed. In this work, freestanding and biodegradable humidity film sensors based on transparent CNFs fabricated by screen printing with two different electrode materials are described. The physical and optical characterization of CNFs is presented together with the electrical characterization of the manufactured devices at different AC frequencies in order to evaluate its performance as humidity sensors.

\section{Results}

\subsection{Physical and optical characterization of the cellulose nanofibers}

The CNF had a charge density of $1.06 \mathrm{mmol} / \mathrm{g}$ arising from carboxylate groups introduced at the cellulose C6 primary hydroxyls during TEMPO-mediated oxidation [25]. The surface charge facilitated the mechanical defibrillation and electrostatic stabilization of CNF in water forming transparent, viscoelastic hydrogels. The fibre diameter was approx. $2.1 \mathrm{~nm}$ as 
determined by Atomic force microscopy (AFM) and the fibre length was between 400 and 1500 nm. The AFM image also shows the typical kinks of CNF, conferring flexibility to the fibres (Fig. 1a) [26].

The CNF hydrogels were solvent cast to render CNF films of 10 and $21 \mathrm{~g} / \mathrm{m}^{2}$ grammage (denoted as type 10 and type 21, respectively). The type 10 film appeared very transparent while the type 21 film was slightly hazy (Fig.1b and Fig. 1c). These observations were confirmed by optical transmittance measurements (Fig. 3) and are attributed to the different grammage of the films.

Scanning Electron Microscope (SEM) images of the film surfaces are shown in Fig. 1d for type 10 and Fig. 1e for type 21 cellulose paper and display the typical dense microstructure of solvent-cast nanocellulose films [26]. The slow drying results in compact fibre arrangements with low porosity and surface roughness [27].

a)

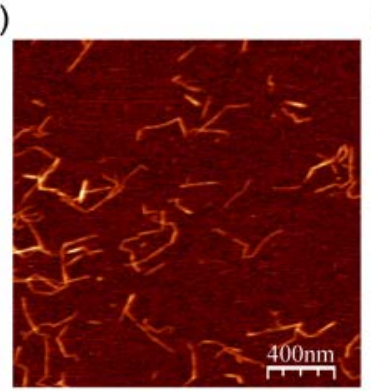

d)

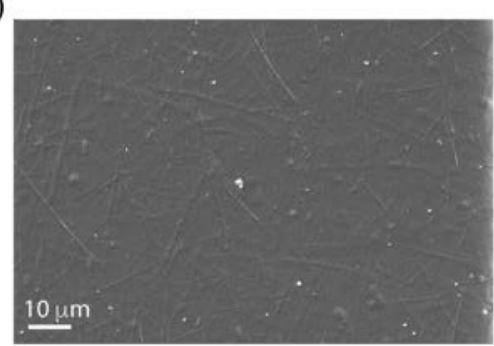

e)

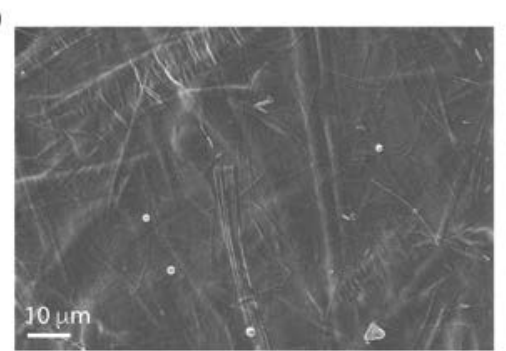

b)

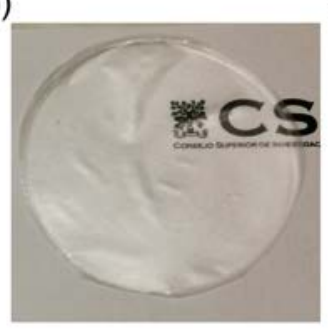

c)

f)

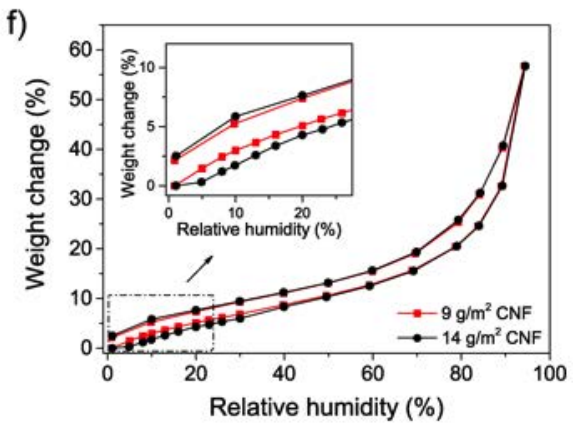

g)

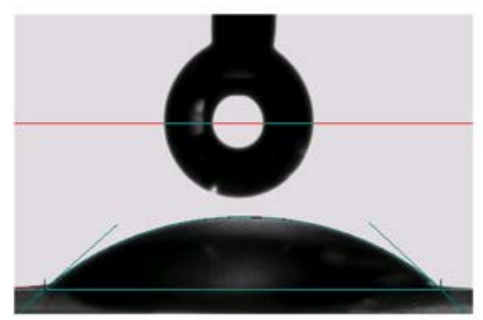

Figure 1. (a) Atomic force microscopy (AFM) image of a single CNF. Optical photographs of CNF films type 10 (b) and type 21 (c). SEM images of (d) type 10 and (e) type 21 cellulose paper. (f) Water sorption isotherm on 9 and $14 \mathrm{~g} / \mathrm{m}^{2} \mathrm{CNF}$ nanopaper. (g) Water contact angle of $9 \mathrm{~g} / \mathrm{m}^{2} \mathrm{CNF}$ film. 
The wetting properties of substrates for humidity sensors are crucial for their sensitivity [19, 28-30]. Therefore, the CNF films were analysed by sampling water sorption isotherms and performing water contact angle measurements. The isotherms provide a quantitative measure of the affinity of a substrate to water and both CNF films display very similar water sorption behaviour with a maximum uptake of $55 \mathrm{wt} \%$ water at $95 \% \mathrm{RH}$ (Fig. 1f). This value is significantly higher than sorption values for conventional pulp paper, which are in the 15-20 wt\% range [31]. The higher affinity of CNF films for water is generally explained with the abundance of surface $\mathrm{OH}$ and COONa groups, the latter introduced during TEMPO-mediated oxidation [32, 33].

The contact angle of sessile water drops of the CNF film is $\left(40^{\circ} \pm 3^{\circ}\right)$ after $5 \mathrm{~s}$ upon drop deposition, which is a clear indication of the hydrophilic character of the film surface. On the other hand, typical filter papers have contact angles $<10^{\circ}$ before the water drop is soaked up by the filter paper due to the capillarity of the porous film. This effect is diminished and delayed by ca. 30 s on CNF films given the more compact fibre arrangement (see Fig. 1d and Fig. 1e). The chemical and textural properties of the CNF films was assessed by Fourier-transform infrared (FTIR) spectroscopy and X-ray powder diffraction (XRD). Fig. 2a presents the FTIR spectrum of the $9 \mathrm{~g} / \mathrm{m}^{2} \mathrm{CNF}$ film, which confirms the presence of sodium carboxylate groups by the $\mathrm{C}=\mathrm{O}$ stretching vibration at $1608 \mathrm{~cm}^{-1}$ [34]. Moreover, the bands at 1425, 1164, 1111 and $899 \mathrm{~cm}^{-1}$ indicate the cellulose crystal structure type I of CNF. Nevertheless, there is also a slight transformation of the cellulose type I crystal structure to type II as evidenced by the shoulder at $1408 \mathrm{~cm}^{-1}$ [35] and possibly attributed to the alkaline conditions during TEMPOmediated oxidation [36].

The X-ray diffractogram in Fig. 2b shows the pattern of the cellulose type I crystal structure with (11̄0), (110), and (200) reflections at 16.1 and $22.5^{\circ}$, respectively. The crystallinity index (C.I.) of the carboxylated cellulose nanofibers is $67 \%$. The C.I. of the bleached eucalyptus pulp, 
the starting material for the cellulose nanofibers, is $81 \%$ [36]. The decrease of C.I. upon carboxylation and nanofibrillation is well-known and attributed to an oxidative attack on the crystal surface during CNF production [25].

a)

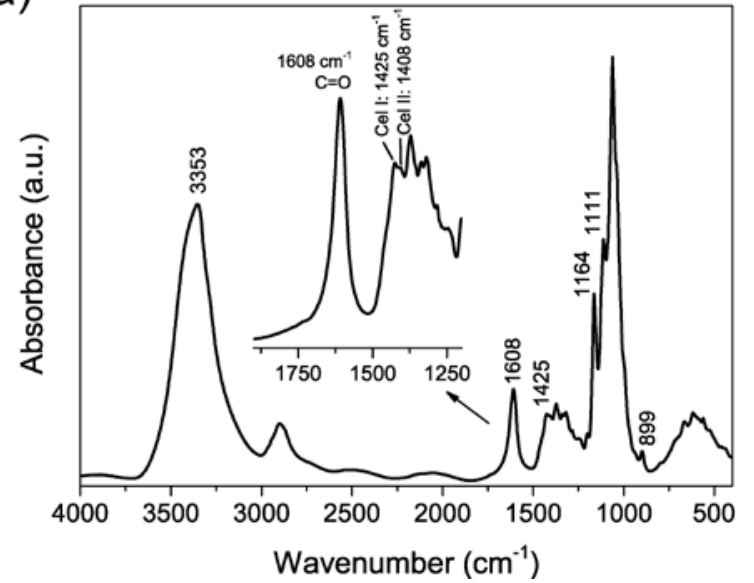

b)

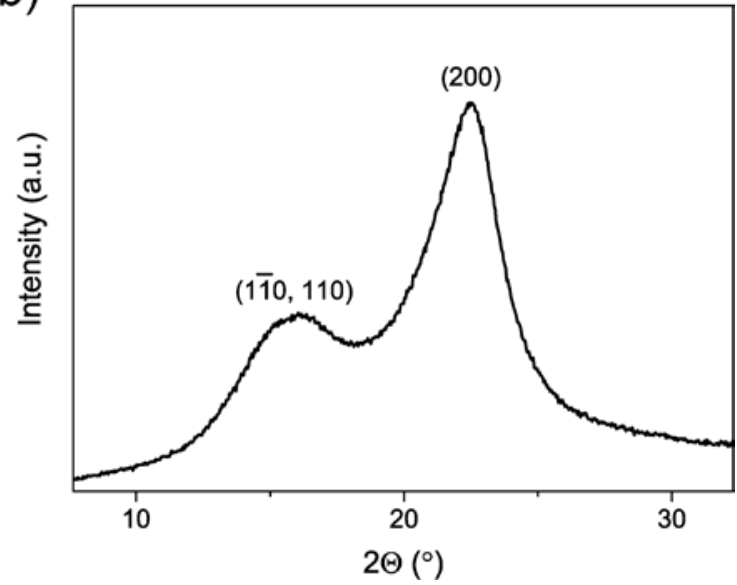

Figure 2. (a) FTIR spectrum of the $9 \mathrm{~g} / \mathrm{m}^{2} \mathrm{CNF}$ film (a) and a magnified view of the $1900-1200 \mathrm{~cm}^{-1}$ region indicating the bands attributed to cellulose type I and type II (inset). (b) XRD pattern of CNF.

\subsection{Physical and electro-optical characterization of the sensors}

The silver interdigitated electrodes (IDEs) had a thickness of $3.9 \mu \mathrm{m}$ and a sheet resistance of $79 \pm 10 \mathrm{~m} \Omega /$ sq., respectively, which results in an electrical conductivity of $0.325 \cdot 10^{7} \mathrm{~S} / \mathrm{m}$.

Compared to the conductivity value for bulk silver at $20^{\circ} \mathrm{C}$, about $(6.3 \pm 0.8) \cdot 10^{7} \mathrm{~S} / \mathrm{m}$, the value for the screen printed films is lowered by a factor of about 20. The lowered conductivity of screen printed silver films is widely observed in literature and attributed to trace contamination of binder materials, solvents, enclosed air pockets and additional resistances that occur at the flake-to-flake interface [37]. In the case of the PEDOT:PSS electrodes, the films had a thickness of $(573 \pm 30) \mathrm{nm}$ and a sheet resistance of $(458 \pm 23) \Omega /$ sq., which gives a conductivity of (3.8 \pm 0.3$) \cdot 10^{3} \mathrm{~S} / \mathrm{m}$. The transmittances of the CNF films and the PEDOT:PSS film are shown in Fig. 3. PEDOT:PSS shows an increased absorption at higher wavelengths, that gives rise to its typical blue appearance [38]. The cellulose papers have a flat transmission profile all over the visible wavelength window, i.e. from 300 to $800 \mathrm{~nm}$. 


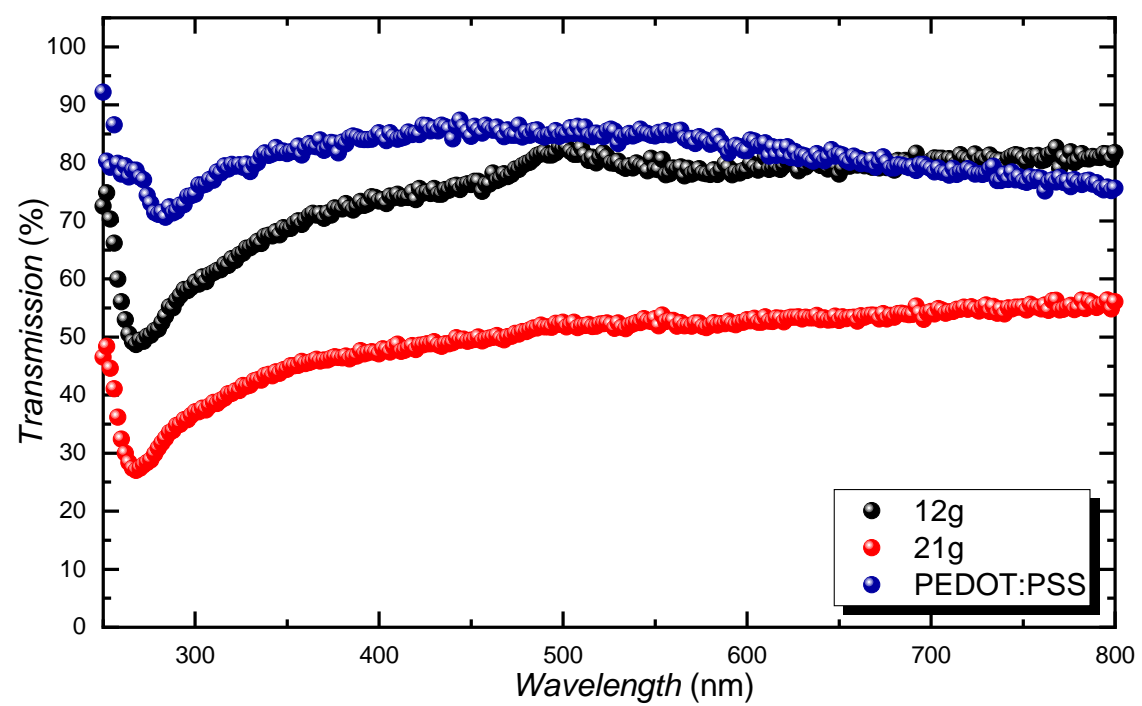

Figure 3. Optical transmittance for the tested CNF substrates and the conductive PEDOT:PSS layer.

The following step was the manufacturing of the devices by defining the IDEs on top of the cellulose films. Fig 4a shows the schematic design of IDE sensor with its dimensions. Fig. 4b and Fig. 4c depict the fabricated sensors on substrate type 21, which is more opaque than substrate type 10, with Ag and PEDOT:PSS electrodes, respectively. Microscope images of these devices are shown in Fig. 4d and Fig. 4e.

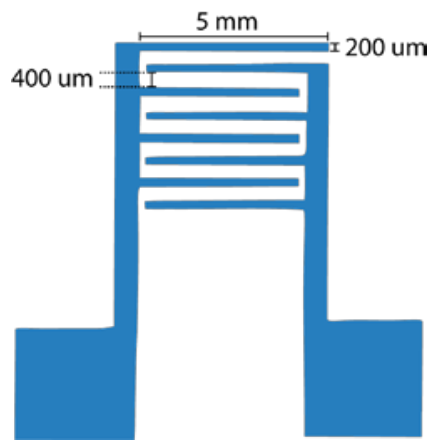

(a)

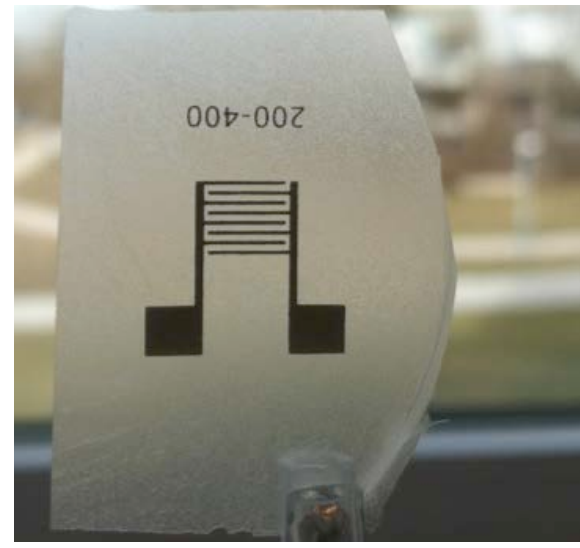

(b)

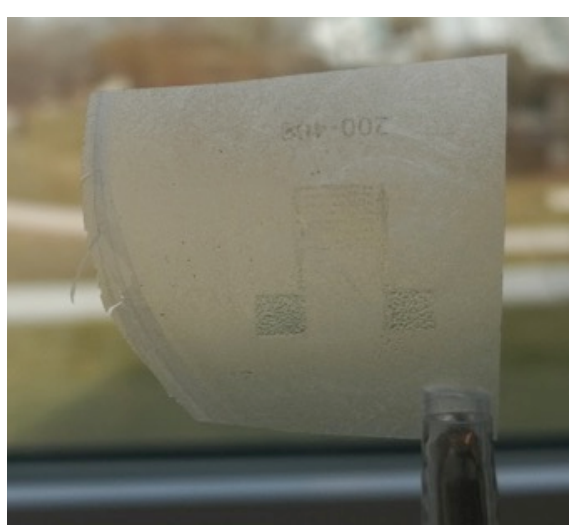

(c) 


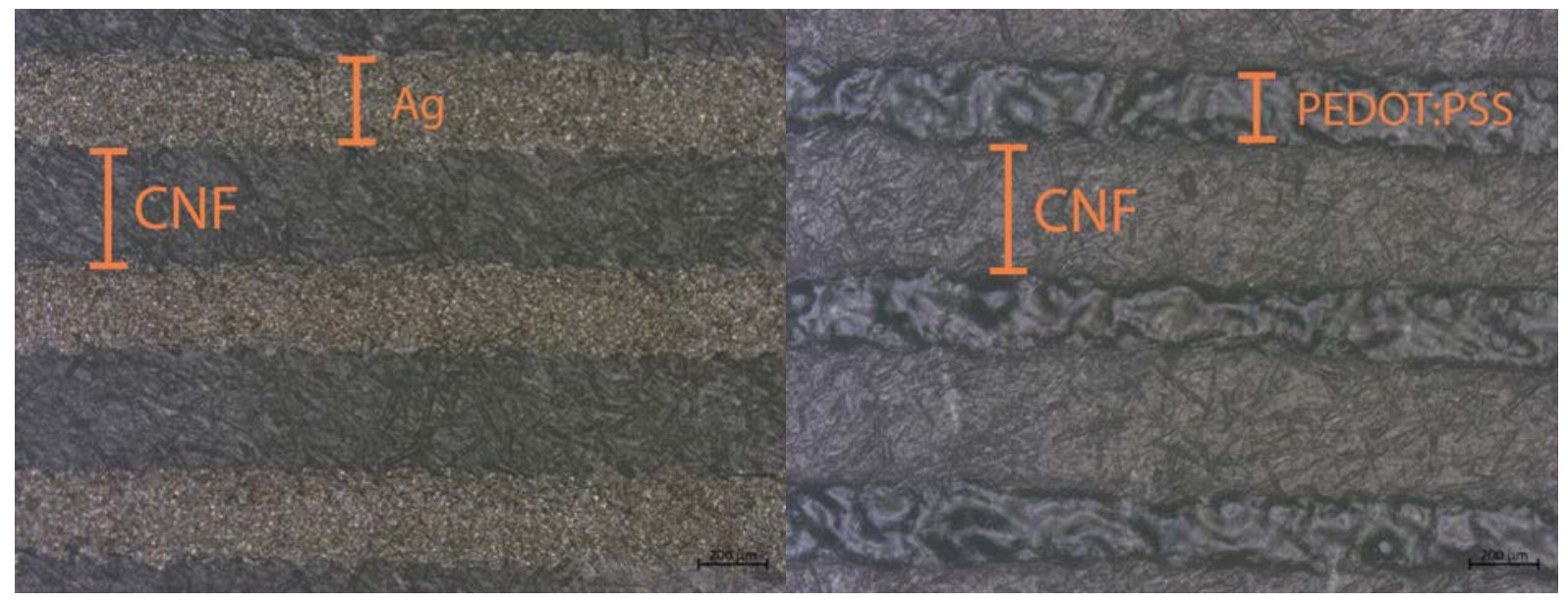

(d)

(e)

Figure 4. Dimensions of the IDE humidity sensor (a). Photos of the fabricated devices on substrate type 21 with Ag electrodes (b) and PEDOT:PSS electrodes (c). Microscope images of devices on substrate type 21 with Ag electrodes (d) and PEDOT:PSS electrodes (e).

\subsection{Response to moisture content}

Once the electrical, physical and optical properties of the substrates and deposited layers were analysed, we tested the fabricated devices in the climatic chamber. The sensing mechanism of the sensor is due to the absorption of water molecules by the CNF films. The presence of water molecules changes the electrical permittivity of the sensing material providing a variation of the resultant measured impedance of the sensor. Fig. 5 shows the impedance response of the sensors at two operating frequencies. Although the shapes remain the same at $100 \mathrm{~Hz}$ and 1 $\mathrm{kHz}$ for the different substrates, it can be noticed that the module decreases with the increase in frequency. Impedance responses with respect to RH are detailed in Fig. S1 and Fig. S2 for the different tested CNF substrates.

In the case of type 21, the module decreases linearly with the increment of the moisture content, whereas type 10 exhibits a low-pass filter shape, where the RH cut-off level is different for PEDOT:PSS (about 70\%RH) electrodes and Ag electrodes (about 35\%RH).

It should be noticed that the data fit to an exponential curve. A characterization of the exponential behaviour in module at $100 \mathrm{~Hz}$ is present in Table 1 . In the case of type 21 devices and type 10 with Ag electrodes, the slope and the range of $\mathrm{RH}$, where the fitting is valid (from $21 \%$ to $83 \% \mathrm{RH}$ ), are very similar, with $\mathrm{R}^{2}=0.97$ at least. However, for type 10 with PEDOT 
electrodes the linear range of $\mathrm{RH}$ (from $70 \%$ to $85 \% \mathrm{RH}$ ) decreases considerably but the slope is $-0.23 \Omega / \% \mathrm{RH}$, which is higher than the other devices.

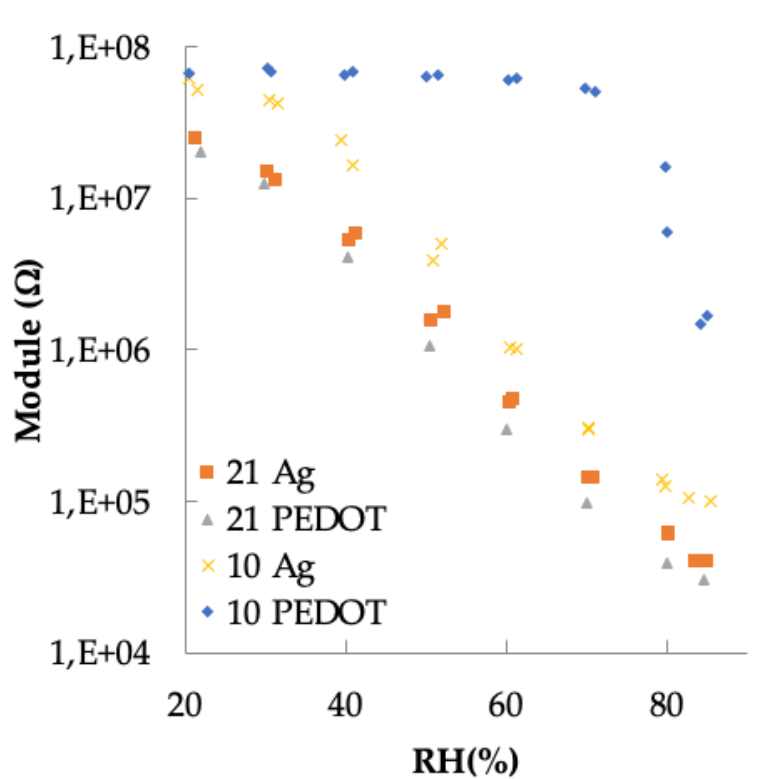

(a)

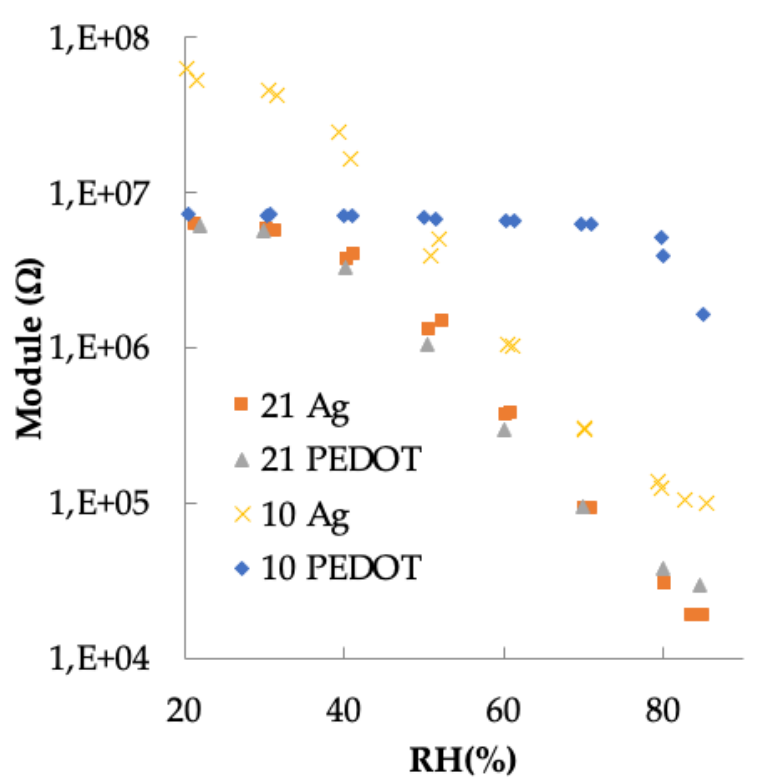

(c)

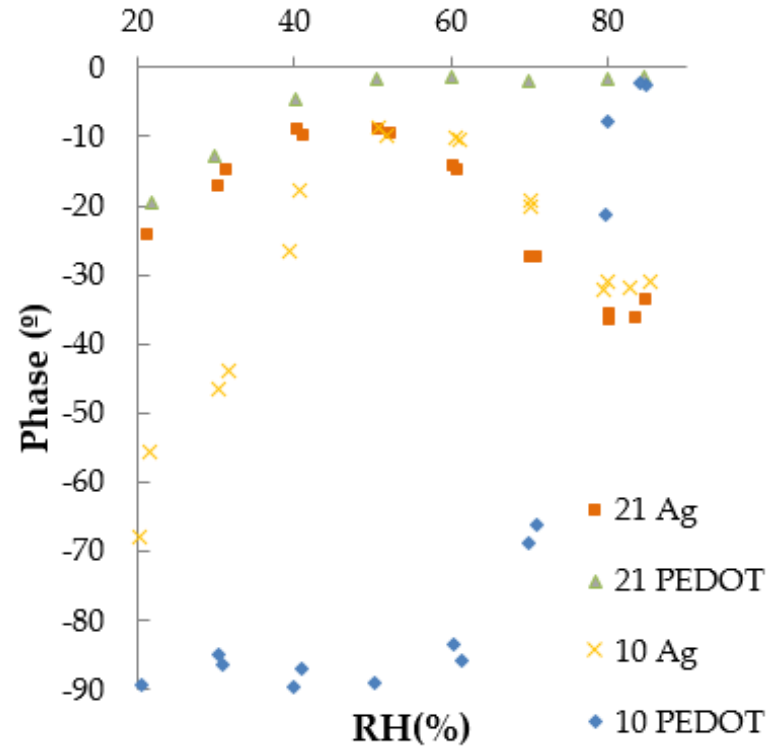

(b)

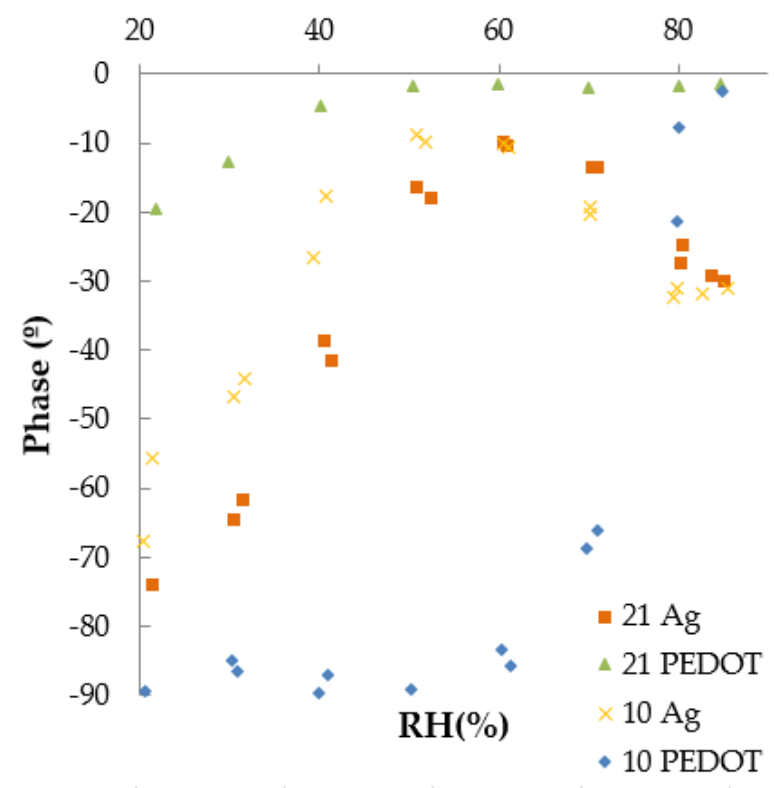

(d)

Figure 5. Impedance response towards RH at $40{ }^{\circ} \mathrm{C}$. (a) Module and (b) Phase at $100 \mathrm{~Hz}$. (c) Module and (d) Phase at $1 \mathrm{kHz}$.

Table 1. Linear ranges and fitting parameters at $100 \mathrm{~Hz}$.

\begin{tabular}{|c|c|c|c|}
\hline Sensor type & Valid range in $\mathrm{RH}(\%)$ & $\mathbf{R}^{2}$ & Sensitivity $(\Omega / \% R H)$ \\
\hline Type 21 Ag & $21.30-84.98$ & 0.9929 & -0.10 \\
\hline Type 21 PEDOT & $21.85-83.60$ & 0.9938 & -0.11 \\
\hline Type 10 Ag & $21.46-85.42$ & 0.9795 & -0.11 \\
\hline Type 10 PEDOT & $69.81-84.97$ & 0.9626 & -0.23 \\
\hline
\end{tabular}


Regarding the dynamic response of the sensors, we calculated the response time of our devices as $\mathrm{t}=\tau$, corresponding to the $63 \%$ of the maximum value of magnitude reached at equilibrium when increasing $\mathrm{RH}$ from $20 \%$ to $80 \%$ at ambient conditions. Equivalent calculations were performed to extract their recovery time, when decreasing $\mathrm{RH}$ from $80 \%$ to $20 \%$ Table 2 summarizes the dynamic response for each one of the fabricated sensors.

Table 1. Time response for RH.

\begin{tabular}{ccc}
\hline Sensor type & Response time (min) & Recovery time (min) \\
\hline $21 \mathrm{Ag}$ & $6.4 \pm 0.4$ & $6.7 \pm 0.3$ \\
\hline $21 \mathrm{PEDOT}$ & $7.1 \pm 0.3$ & $7.9 \pm 0.5$ \\
\hline $10 \mathrm{Ag}$ & $6.1 \pm 0.3$ & $6.4 \pm 0.3$ \\
\hline $10 \mathrm{PEDOT}$ & $6.9 \pm 0.4$ & $7.6 \pm 0.4$ \\
\hline
\end{tabular}

Regarding the device stability, we observed virtually no variation in the sensors' performance when we characterized them daily over the course of a week. The observed variation among calibration curves were below $0.4 \%$.

\subsection{Response to temperature}

Temperature influence was the other environmental parameter analysed in this paper. Fig. 6 presents the impedance response towards temperature of the sensors at $100 \mathrm{~Hz}$ and $1 \mathrm{kHz}$. Impedance responses towards temperature are found in Fig. S3 and Fig. S4 for the different tested CNF substrates characterized at different frequencies. The influence of temperature is more evident for Ag electrodes devices than for PEDOT:PSS-based ones. Regarding the differences between substrates, type 21 shows a higher dependence towards temperature than 10-type. 


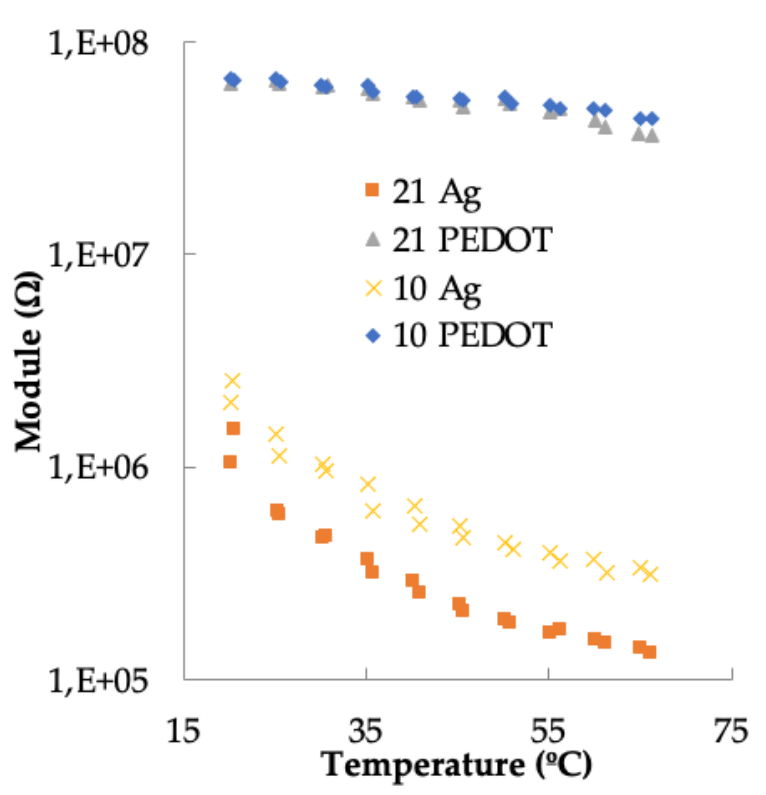

(a)

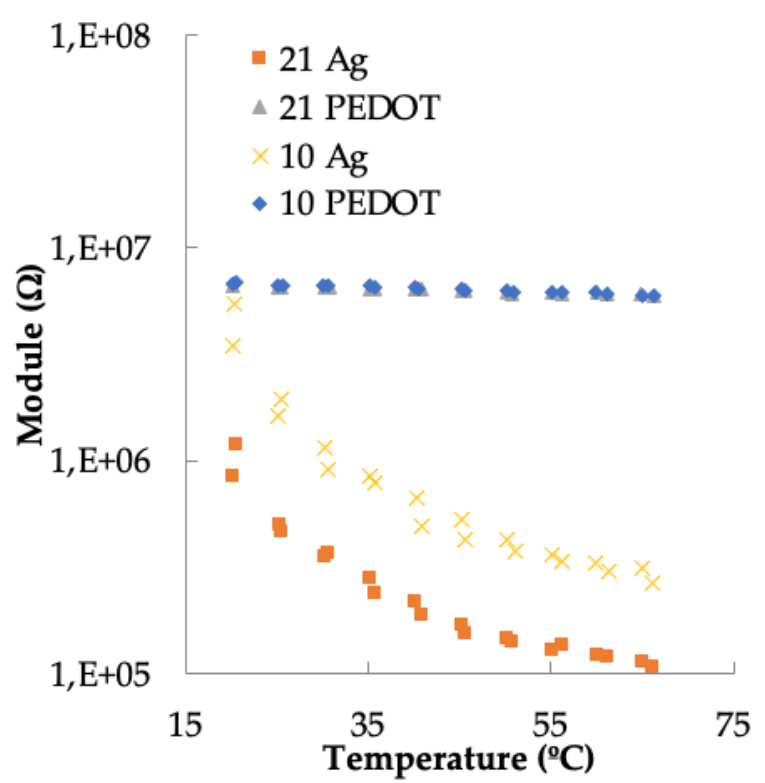

(c)

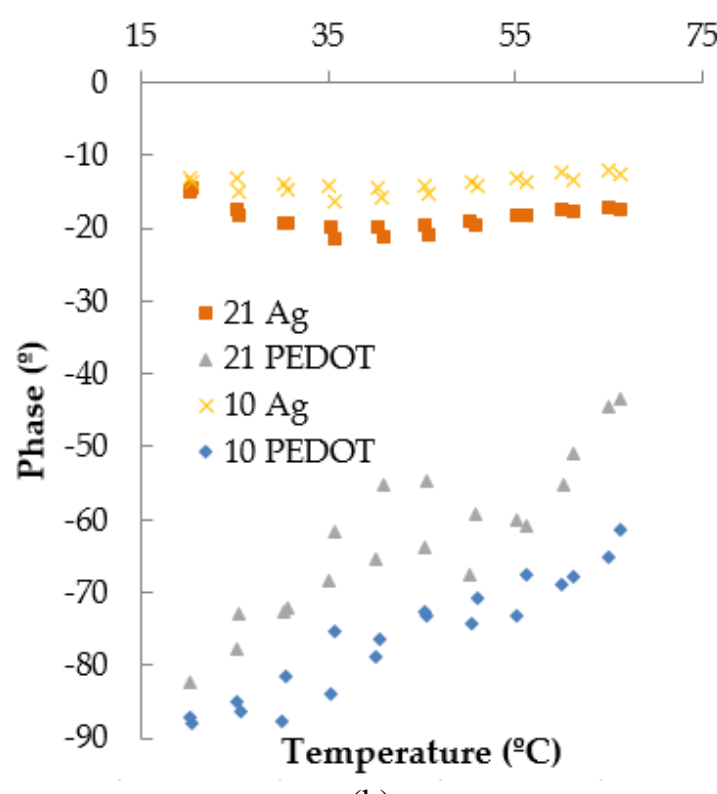

(b)

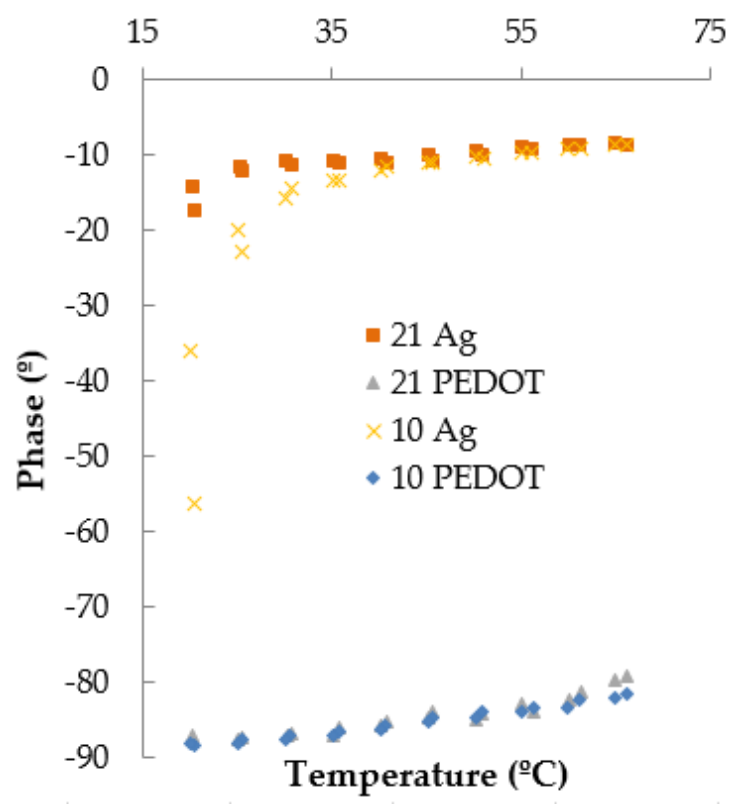

(d)

Figure 6. Impedance response towards Temperature at 55\%RH. (a) Module and (b) Phase at $100 \mathrm{~Hz}$. (c) Module and (d) Phase at $1 \mathrm{kHz}$.

\section{Discussion}

In the following, the sensors reported in this work will be compared to other self-supported film humidity sensors with similar characteristics. Table 2 presents a comparison across some similar humidity sensors reported in literature. The 21-Type devices present a linear variation of the module from $20 \%$ up to $85 \% \mathrm{RH}$, which is comparable with other transparent cellulosebased sensors. For example, cellulose-based sensors were reported by Syrový et al. [21] and Wang et al. [20] that worked in the RH ranges of $20-90 \%$ and $11-97 \% \mathrm{RH}$, respectively. Thus, 
in terms of RH ranges, the moisture sensors reported here work within similar ranges like the ones reported in literature based on transparent cellulose substrates. Transparent, selfsupported film sensors based on other substrates are found in literature. Yang et al. [39] reported a transparent humidity sensor based on PET, which presents a wide operation range from 0 to 100\%RH similar to Kafy et al. [29] and Guo et al. [30]. Besides, transparent humidity sensors built with others substrates such as organohydrogels and PMDS were reported with a RH ranges of $20-70 \%$ and $10-70 \%$, respectively [40, 41]. In spite of the high performance of the sensors based on PET and the other mentioned substrates, these sensors are not build with biodegradable materials like cellulose. While PET substrates are also transparent, they are not biodegradable unlike the humidity sensors reported in this work, which show both characteristics due to the employed substrate and the use of PEDOT:PSS electrodes.

Table 2. Comparison between different humidity sensors reported in literature. n.d. = not determined. Temp. $=$ Temperature. Trans. $=$ Transparent.

\begin{tabular}{|c|c|c|c|c|c|c|c|}
\hline Materials & Fabrication & Output & RH & Temp. & Trans. & Sensitivity & Ref \\
\hline $\begin{array}{l}\text { Poly (ionic liquid)s } \\
\text { on paper }\end{array}$ & Drop-casting & Impedance & $11-95 \%$ & n.d. & No & $961.3\left(\mathrm{Z}_{0} / \mathrm{Z}\right)$ & {$[28]$} \\
\hline GO on PET & $\begin{array}{l}\text { Spin-Coated + } \\
\text { laser }\end{array}$ & Impedance & $11-95 \%$ & n.d. & Yes & $\begin{array}{l}-0.06 \\
(\mathrm{Z} / \% \mathrm{RH})\end{array}$ & {$[30]$} \\
\hline $\begin{array}{l}\text { Nanofibrillated } \\
\text { cellulose/MWCNT } \\
\text { s composite film }\end{array}$ & $\begin{array}{l}\text { TEMPO/NaClO/ } \\
\text { NaBr oxidation } \\
\text { +mechanical } \\
\text { homogenization }\end{array}$ & Current & $11-95 \%$ & n.d. & No & $69 \%(\Delta \mathrm{I} / \mathrm{I} 0)$ & [19] \\
\hline $\begin{array}{l}\text { cellulose/KOH } \\
\text { composite ionic } \\
\text { film (CKF) }\end{array}$ & $\begin{array}{l}\text { Cellulose/BzMe3 } \\
\text { NOH hydrogel } \\
\text { film + immersion } \\
\text { in KOH solution }\end{array}$ & Resistance & $11-97 \%$ & $\begin{array}{l}10- \\
70^{\circ} \mathrm{C}\end{array}$ & Yes & $\begin{array}{l}-0.05 \\
(\mathrm{Z} / \% \mathrm{RH})\end{array}$ & {$[20]$} \\
\hline $\begin{array}{l}\text { CNF (free-standing } \\
\text { film) }\end{array}$ & Screen printing & Impedance & $20-90 \%$ & n.d. & Yes & $\begin{array}{l}-0.11 \\
(\mathrm{Z} / \% \mathrm{RH})\end{array}$ & {$[21]$} \\
\hline CNC-GO on PET & Drop-casting & Capacitance & $30-90 \%$ & n.d. & Yes & $\begin{array}{l}0.141 \\
(\mathrm{Cr} / \% \mathrm{RH})\end{array}$ & [29] \\
\hline $\begin{array}{l}\text { ITO and } \mathrm{MoO}_{3} \text { on } \\
\text { PET }\end{array}$ & $\begin{array}{l}\text { Spin-coated }+ \\
\text { photolitography }\end{array}$ & Current & $0-100 \%$ & n.d. & Yes & $\begin{array}{l}0.05 \\
(\mathrm{~A} / \% \mathrm{RH})\end{array}$ & [39] \\
\hline Organohydrogel & $\begin{array}{l}\text { Solvent exchange } \\
\text { from synthesized } \\
\text { DN hydrogel }\end{array}$ & $\begin{array}{l}\text { Transconduc- } \\
\text { tance }\end{array}$ & $20-70 \%$ & n.d. & Yes & $\begin{array}{l}10 \% \\
(\Delta \mathrm{G} / \mathrm{G} 0)\end{array}$ & [40] \\
\hline $\begin{array}{l}\text { R-GO/PU on } \\
\text { PDMS }\end{array}$ & Spin-Coated & Resistance & $10-70 \%$ & n.d. & Yes & $\begin{array}{l}0.11 \% \\
(\Delta \mathrm{R} / \mathrm{R} 0)\end{array}$ & [41] \\
\hline $\begin{array}{l}\text { Graphite ink on } \\
\text { Whatman }\end{array}$ & Craft-printing & Current & $30-80 \%$ & n.d. & No & $\begin{array}{l}2.925 \\
(\mathrm{~A} / \% \mathrm{RH})\end{array}$ & [5] \\
\hline CNF 21-Type (Ag) & Screen printing & Impedance & $20-85 \%$ & $\begin{array}{l}20- \\
66^{\circ} \mathrm{C}\end{array}$ & Yes & $\begin{array}{l}-0.10 \\
(\Omega / \% \mathrm{RH})\end{array}$ & $\begin{array}{l}\text { This } \\
\text { work }\end{array}$ \\
\hline
\end{tabular}


As abovementioned, our CNF-based humidity sensors present a transparency feature unlike other sensors fabricated on paper substrates like the ones reported by Zhao et al. [28], Güder et al. [5] and Zhu et al. [19].

In the case of the sensor type 21 with Ag electrodes, a dependence with temperature is noticed within the range from $20^{\circ} \mathrm{C}$ to $65^{\circ} \mathrm{C}$ at $55 \% \mathrm{RH}$. All the sensors presented in Table 2 have been tested in RH ranges similar to our sensors, however only one of these has been tested over a temperature range as well. The cellulose-based sensors reported by Wang et al. were characterized within a temperature range from $10^{\circ} \mathrm{C}$ up to $70^{\circ} \mathrm{C}$ at $40 \% \mathrm{RH}$ [20]. Comparing it with our sensors, the devices characterized in that work present a very similar operation range of temperature at higher RH values. In summary, sensor type 21 with Ag electrodes shows an adequate performance as a hybrid humidity-temperature sensor for several frequencies. The RH and temperature ranges in which the sensors were tested are practical operation ranges for several applications such as air conditions controlling, measuring body temperature and respiration for detecting diseases and food quality monitoring by smart packaging [42-45].

Regarding the fabrication techniques, while both drop-casting and spin-coating methods are employed in several works, our sensors are manufactured by screen printing requiring only onestep to define the electrodes on top of the CNF film, which directly acts as sensitive layer. This method is much more reproducible and the sensor layout can be easily re-designed. Besides, our one-step fabrication method reduces the time and cost of fabrication with respect to others techniques.

\section{Conclusions}

Sustainable development has become a main topic within the IoT industry. In this regard, green electronics is attracting much attention in order to reduce electronics wastes and toxic residues during fabrication processes. In addition, biodegradable materials like CNF have been gaining 
importance for building environmental-friendly, wearable devices due to the additional and complementary properties, such as flexibility, transparency and cost-effectiveness. Transparent devices avoid visual obstruction of the surface where the devices are deployed. This feature evades some practical limitations which facilities the design of end-user devices. Therefore, the main objective of this work is to develop freestanding, transparent and biodegradable humidity film sensors and analyse their performance.

In this work, transparent biodegradable humidity sensors were reported based on CNF. Four different devices were manufactured combining two different CNF films (10 and $21 \mathrm{~g} / \mathrm{m}^{2}$ grammage) with two kind of conductive pastes (PEDOT:PSS and Ag) to define the electrodes. In particular, the type 21 device with Ag electrodes presents a competitive performance compared with others humidity sensors found in literature. This device displays an exponential resistance behaviour within a $\mathrm{RH}$ range between $20-85 \%$ at $100 \mathrm{~Hz}$ according to the sensors reported in literature. Moreover, this sensor also operates within a temperature range from $20^{\circ} \mathrm{C}$ up to $65^{\circ} \mathrm{C}$ at $55 \% \mathrm{RH}$. Such temperature and $\mathrm{RH}$ rages make this device suitable to work as hybrid humidity-temperature sensor for several environmental conditions such as air condition monitoring, smart food packaging and respiration and body temperature monitoring. Likewise, the type 21 sensor with PEDOT:PSS electrodes exhibits a similar RH range making this combination of materials a promising alternative for transparent sensors being completely biodegradable. In conclusion, the transparent and biodegradable humidity sensor reported in this work is a good solution for the currently scenario in IoT green industry.

\section{Experimental Section}

Preparation of the nanocellulose films: Cellulose nanofibers (CNFs) were extracted as described in [36] from never-dried, bleached eucalyptus pulp kindly provided by La Montañanesa (Grupo Torraspapel, Zaragoza, Spain). In brief, an aqueous suspension of the pulp was subjected to a TEMPO-mediated oxidation process to render carboxylated nanofibers (1.06 
mmol $\mathrm{g}^{-1}$ charge as determined by conductometric titration). Subsequent mechanical defibrillation was achieved with a high-pressure microfluidizer (M-110P, Microfluidics Corp., USA) with 100 and $200 \mu \mathrm{m}$ interaction chambers operated at 1500 bar. The resulting CNF dispersion was ultrasonicated for 2 min and centrifuged at $6000 \mathrm{rpm}$ for $25 \mathrm{~min}$ in order to remove fibre aggregates. The final, transparent suspension had a concentration of $0.23 \mathrm{wt} \%$.

The CNF films were prepared by solvent casting of the suspension in polystyrene dishes and controlled drying at $30{ }^{\circ} \mathrm{C}$ and $50 \% \mathrm{RH}$ in a climatic chamber (CLIMACELL EVO). The grammage of the films was 10 and $21 \mathrm{~g} / \mathrm{m}^{2}$ (referred to as type 10 and type 21 films). 2,2,6,6tetramethylpiperidine-1-oxyl radical (TEMPO), sodium bromide ( $\mathrm{NaBr}$ ), sodium hypochlorite solution $(\mathrm{NaClO})$ and $\mathrm{NaOH}$ used during the $\mathrm{CNF}$ extraction process were purchased from Sigma-Aldrich.

Sensor fabrication: Interdigitated electrodes (IDE) were defined on the transparent cellulose paper by screen printing of conductive pastes with a manual screen printer Flat-DX200 from Siebdruckversand (Magdeburg, Germany). The utilized screen frames had a mesh count of 120 T/cm (threads per $\mathrm{cm}$ ) and the electrodes were deposited with only one printing cycle. In particular, two different pastes were used: silver flakes (product name: 1010 from Loctite) and poly(3,4-ethylenedioxythiophene) (PEDOT:PSS) (product number: 655201 from Sigma Aldrich). After the printing process, the substrates with the freshly printed sensors were dried in a Universal Oven UF55 from Memmert (Schwabach, Germany) at a temperature of $60{ }^{\circ} \mathrm{C}$ for 10 min. To establish an electrical connection, a SubMiniature version A (SMA) male connector was glued to the end points of the IDEs with silver paste.

Structural Characterization: AFM images of CNF samples were acquired in modulated amplitude mode under ambient conditions with a Cervantes instrument from 
Nanotecelectrónica S.L. (Spain) equipped with Nanosensors PPP-FMR cantilevers having a spring constant of $1.5 \mathrm{~N} / \mathrm{m}$ and a resonance frequency of $75 \mathrm{kHz}$.

SEM-images were recorded with an NVision40 FESEM from Carl Zeiss (Oberkochen, Germany) at an acceleration voltage of $7 \mathrm{kV}$, an extraction voltage of $5 \mathrm{kV}$ and a working distance of 5-6 mm, which was optimized to achieve the best image quality. The transmittance spectra in the visible range were recorded using a $300 \mathrm{~W}$ xenon arc lamp, chopped at a frequency of $210 \mathrm{~Hz}$. The light passes through an Oriel Cornerstone 260 1/4 monochromator and a silicon based photodiode with a transconductance amplifier connected to a 70105 Oriel Merlin digital lock in amplifier from Newport Corporation (Irvine, California, USA). To calibrate the photodiode, a glass substrate was employed to determine the unperturbed of the studied films.

Electrical Characterization: Sheet resistances were measured with a four-point probe head from Jandel (Linslade, UK) connected to a B2901A Keysight (Santa Rosa, CA, USA) source measuring unit (SMU). All measurements were performed with a constant current of $1 \mathrm{~mA}$. ADekTak XT profilometer from Bruker (Billerica, USA) was employed for the determination of thicknesses. The electrical measurements were performed with an impedance analyser (Keysight E4990A) with an impedance probe kit (42941A). The setup was automated with LabVIEW 2016 from National Instruments (Austin, Texas, USA). The excitation voltage applied in all measurements was $\mathrm{V}_{\mathrm{DC}}=0$ and $\mathrm{V}_{\mathrm{AC}}=500 \mathrm{mV}$ within the frequency range from $100 \mathrm{~Hz}$ to $10 \mathrm{MHz}$. To compensate the parasitic elements, a calibration was done as the one described in a previous work[46]. The devices under test (DUTs) were placed in a climatic chamber (VLC4006) with RH and temperature control. For the RH sensing, the moisture content was ramped in $10 \%$ steps and held for $1 \mathrm{~h}$ to ensure a stable value in the whole chamber volume. A similar approach was used for temperature sensing with $5^{\circ} \mathrm{C}$ steps for $1 \mathrm{~h}$. 


\section{Acknowledgements}

This work was partially funded by the fellowship H2020-MSCA-IF-2017-794885-SELFSENS.

BW acknowledges financial support from MINECO/FEDER EU (projects MAT2015-71117R, PID2019-107022RJ-I00) and for an IJCI contract (IJCI-2015-23886). The authors thank Dr. Asenjo for the AFM work.

\section{Data Availability}

Data available on request from the authors. 


\section{References}

[1] Y. Bouzembrak, M. Klüche, A. Gavai, H.J. Marvin, Internet of Things in food safety: Literature review and a bibliometric analysis, Trends in Food Science \& Technology (2019). [2] G. Hancke, B. Silva, G. Hancke Jr, The role of advanced sensing in smart cities, Sensors 13(1) (2013) 393-425.

[3] M.A. Najeeb, Z. Ahmad, R.A. Shakoor, Organic thin - film capacitive and resistive humidity sensors: a focus review, Advanced Materials Interfaces 5(21) (2018) 1800969. [4] D. Thakur, Y. Kumar, A. Kumar, P.K. Singh, Applicability of Wireless Sensor Networks in Precision Agriculture: A Review, Wireless Personal Communications 107(1) (2019) 471512.

[5] F. Güder, A. Ainla, J. Redston, B. Mosadegh, A. Glavan, T. Martin, G.M. Whitesides, Paper - based electrical respiration sensor, Angewandte Chemie International Edition 55(19) (2016) 5727-5732.

[6] Y. Luo, Y. Pei, X. Feng, H. Zhang, B. Lu, L. Wang, Silk fibroin based transparent and wearable humidity sensor for ultra-sensitive respiration monitoring, Materials Letters 260 (2020) 126945.

[7] Z. Chen, C. Lu, Humidity sensors: a review of materials and mechanisms, Sensor Letters 3(4) (2005) 274-295.

[8] Y.H. Jung, H. Zhang, S. Gong, Z. Ma, High-performance green semiconductor devices: materials, designs, and fabrication, Semiconductor Science and Technology 32(6) (2017) 063002.

[9] M. Jian, Y. Zhang, Z. Liu, Natural Biopolymers for Flexible Sensing and Energy Devices, Chinese Journal of Polymer Science (2020) 1-32.

[10] T. Mokhena, M. John, Cellulose nanomaterials: new generation materials for solving global issues, Cellulose (2019) 1-46. 
[11] L.H. Nguyen, S. Naficy, R. Chandrawati, F. Dehghani, Nanocellulose for Sensing Applications, Advanced Materials Interfaces 6(18) (2019) 1900424.

[12] L. Bacakova, J. Pajorova, M. Tomkova, R. Matejka, A. Broz, J. Stepanovska, S. Prazak, A. Skogberg, S. Siljander, P. Kallio, Applications of Nanocellulose/Nanocarbon Composites: Focus on Biotechnology and Medicine, Nanomaterials 10(2) (2020) 196.

[13] Q. Qian, Y. Wang, M. Zhang, L. Chen, J. Feng, Y. Wang, Y. Zhou, Ultrasensitive paperbased polyaniline/graphene composite strain sensor for sign language expression, Composites Science and Technology 181 (2019) 107660.

[14] Y. Zhao, M. Ren, Y. Shang, J. Li, S. Wang, W. Zhai, G. Zheng, K. Dai, C. Liu, C. Shen, Ultra-sensitive and durable strain sensor with sandwich structure and excellent antiinterference ability for wearable electronic skins, Composites Science and Technology 200 (2020) 108448.

[15] X. Yue, Y. Jia, X. Wang, K. Zhou, W. Zhai, G. Zheng, K. Dai, L. Mi, C. Liu, C. Shen, Highly stretchable and durable fiber-shaped strain sensor with porous core-sheath structure for human motion monitoring, Composites Science and Technology 189 (2020) 108038. [16] V.R. Feig, H. Tran, Z. Bao, Biodegradable polymeric materials in degradable electronic devices, ACS central science 4(3) (2018) 337-348.

[17] X. Zeng, L. Deng, Y. Yao, R. Sun, J. Xu, C.-P. Wong, Flexible dielectric papers based on biodegradable cellulose nanofibers and carbon nanotubes for dielectric energy storage, Journal of Materials Chemistry C 4(25) (2016) 6037-6044.

[18] H. Koga, T. Saito, T. Kitaoka, M. Nogi, K. Suganuma, A. Isogai, Transparent, conductive, and printable composites consisting of TEMPO-oxidized nanocellulose and carbon nanotube, Biomacromolecules 14(4) (2013) 1160-1165.

[19] P. Zhu, Y. Liu, Z. Fang, Y. Kuang, Y. Zhang, C. Peng, G. Chen, Flexible and highly sensitive humidity sensor based on cellulose nanofibers and carbon nanotube composite film, Langmuir 35(14) (2019) 4834-4842. 
[20] Y. Wang, L. Zhang, J. Zhou, A. Lu, Flexible and Transparent Cellulose-Based Ionic Film as a Humidity Sensor, ACS Applied Materials \& Interfaces 12(6) (2020) 7631-7638.

[21] T. Syrový, S. Maronová, P. Kuberský, N.V. Ehman, M.E. Vallejos, S. Pretl, F.E. Felissia, M.C. Area, G. Chinga - Carrasco, Wide range humidity sensors printed on biocomposite films of cellulose nanofibril and poly (ethylene glycol), Journal of Applied Polymer Science 136(36) (2019) 47920.

[22] T. Park, N. Kim, D. Kim, S.-W. Kim, Y. Oh, J.-K. Yoo, J. You, M.-K. Um, An Organic/Inorganic Nanocomposite of Cellulose Nanofibers and ZnO Nanorods for Highly Sensitive, Reliable, Wireless, and Wearable Multifunctional Sensor Applications, ACS applied materials \& interfaces 11(51) (2019) 48239-48248.

[23] V. Anju, P. Jithesh, S.K. Narayanankutty, A novel humidity and ammonia sensor based on nanofibers/polyaniline/polyvinyl alcohol, Sensors and Actuators A: Physical 285 (2019) $35-44$.

[24] M.M. González del Campo, M. Darder, P. Aranda, M. Akkari, Y. Huttel, A. Mayoral, J. Bettini, E. Ruiz - Hitzky, Functional hybrid nanopaper by assembling nanofibers of cellulose and sepiolite, Advanced Functional Materials 28(27) (2018) 1703048. [25] A. Isogai, T. Saito, H. Fukuzumi, TEMPO-oxidized cellulose nanofibers, Nanoscale 3(1) (2011) 71-85.

[26] B. Wicklein, A.M. Diem, A. Knöller, M.S. Cavalcante, L. Bergström, J. Bill, Z. Burghard, Dual - Fiber Approach toward Flexible Multifunctional Hybrid Materials, Advanced Functional Materials 28(27) (2018) 1704274.

[27] A. Barhoum, P. Samyn, T. Öhlund, A. Dufresne, Review of recent research on flexible multifunctional nanopapers, Nanoscale 9(40) (2017) 15181-15205. 
[28] H. Zhao, X. Lin, R. Qi, J. Dai, S. Liu, T. Fei, T. Zhang, A Composite Structure of In Situ Cross-Linked Poly (Ionic Liquid) s and Paper for Humidity-Monitoring Applications, IEEE Sensors Journal 19(3) (2018) 833-837.

[29] A. Kafy, A. Akther, M.I. Shishir, H.C. Kim, Y. Yun, J. Kim, Cellulose nanocrystal/graphene oxide composite film as humidity sensor, Sensors and Actuators A: Physical 247 (2016) 221-226.

[30] L. Guo, H.-B. Jiang, R.-Q. Shao, Y.-L. Zhang, S.-Y. Xie, J.-N. Wang, X.-B. Li, F. Jiang, Q.-D. Chen, T. Zhang, Two-beam-laser interference mediated reduction, patterning and nanostructuring of graphene oxide for the production of a flexible humidity sensing device, Carbon 50(4) (2012) 1667-1673.

[31] M. Parker, J. Bronlund, A. Mawson, Moisture sorption isotherms for paper and paperboard in food chain conditions, Packaging Technology and Science: An International Journal 19(4) (2006) 193-209.

[32] K.J. De France, T. Hoare, E.D. Cranston, Review of hydrogels and aerogels containing nanocellulose, Chemistry of Materials 29(11) (2017) 4609-4631.

[33] U. Freudenberg, R. Zimmermann, K. Schmidt, S.H. Behrens, C. Werner, Charging and swelling of cellulose films, Journal of colloid and interface science 309(2) (2007) 360-365. [34] S. Fujisawa, Y. Okita, H. Fukuzumi, T. Saito, A. Isogai, Preparation and characterization of TEMPO-oxidized cellulose nanofibril films with free carboxyl groups, Carbohydrate Polymers 84(1) (2011) 579-583.

[35] S.Y. Oh, D.I. Yoo, Y. Shin, G. Seo, FTIR analysis of cellulose treated with sodium hydroxide and carbon dioxide, Carbohydrate research 340(3) (2005) 417-428.

[36] Ú. Fillat, B. Wicklein, R. Martin-Sampedro, D. Ibarra, E. Ruiz-Hitzky, C. Valencia, A. Sarrión, E. Castro, M.E. Eugenio, Assessing cellulose nanofiber production from olive tree pruning residue, Carbohydrate polymers 179 (2018) 252-261. 
[37] R. Faddoul, N. Reverdy-Bruas, A. Blayo, Formulation and screen printing of water based conductive flake silver pastes onto green ceramic tapes for electronic applications, Materials Science and Engineering: B 177(13) (2012) 1053-1066.

[38] T.-R. Chou, S.-H. Chen, Y.-T. Chiang, Y.-T. Lin, C.-Y. Chao, Highly conductive PEDOT: PSS films by post-treatment with dimethyl sulfoxide for ITO-free liquid crystal display, Journal of Materials Chemistry C 3(15) (2015) 3760-3766.

[39] J. Yang, R. Shi, Z. Lou, R. Chai, K. Jiang, G. Shen, Flexible smart noncontact control systems with ultrasensitive humidity sensors, Small 15(38) (2019) 1902801.

[40] J. Wu, Z. Wu, H. Xu, Q. Wu, C. Liu, B.-R. Yang, X. Gui, X. Xie, K. Tao, Y. Shen, An intrinsically stretchable humidity sensor based on anti-drying, self-healing and transparent organohydrogels, Materials Horizons 6(3) (2019) 595-603.

[41] T.Q. Trung, S. Ramasundaram, N.-E. Lee, Transparent, stretchable, and rapid-response humidity sensor for body-attachable wearable electronics, Nano Research 10(6) (2017) 20212033.

[42] G. Coulby, A. Clear, O. Jones, A. Godfrey, A Scoping Review of Technological Approaches to Environmental Monitoring, International Journal of Environmental Research and Public Health 17(11) (2020) 3995.

[43] H. Beshai, G.K. Sarabha, P. Rathi, A.U. Alam, M.J. Deen, Freshness Monitoring of Packaged Vegetables, Applied Sciences 10(21) (2020) 7937.

[44] R. Chaisaen, P. Autthasan, N. Mingchinda, P. Leelaarporn, N. Kunaseth, S. Tammajarung, P. Manoonpong, T. Wilaiprasitporn, Decoding EEG Rhythms During Action Observation, Motor Imagery, and Execution for Standing and Sitting, arXiv preprint arXiv:2004.04107 (2020).

[45] Z. Lou, L. Wang, K. Jiang, Z. Wei, G. Shen, Reviews of wearable healthcare systems: Materials, devices and system integration, Materials Science and Engineering: R: Reports 140 (2020) 100523. 
[46] A. Rivadeneyra, J. Fernández-Salmerón, M. Agudo, J. López-Villanueva, L. CapitanVallvey, A. Palma, Design and characterization of a low thermal drift capacitive humidity sensor by inkjet-printing, Sensors and Actuators B: Chemical 195 (2014) 123-131. 


\section{Supporting Information for:}

\section{Cellulose nanofibers as substrate for flexible and biodegradable moisture sensors}

Almudena Rivadeneyra ${ }^{*}, 1$, Antonio Marín-Sánchez ${ }^{2}$, Bernd Wicklein ${ }^{3}$, José F. Salmerón ${ }^{4}$, Encarnación Castillo ${ }^{1}$, Marco Bobinger ${ }^{4}$ and Alfonso Salinas-Castillo ${ }^{2}$

${ }^{1}$ Department of Electronics and Computer Technology, University of Granada, 18071, Granada (Spain)

${ }^{2}$ Department of Analytical Chemistry, University of Granada, 18071, Granada (Spain)

${ }^{3}$ Instituto de Ciencia de Materiales de Madrid (ICMM), Consejo Superior de Investigaciones Científicas (CSIC), 28049, Madrid (Spain)

${ }^{4}$ Institute for Nanoelectronics, Technical University of Munich, 80333, Munich (Germany)

*Corresponding author: arivadeneyra@ugr.es

Response to moisture content
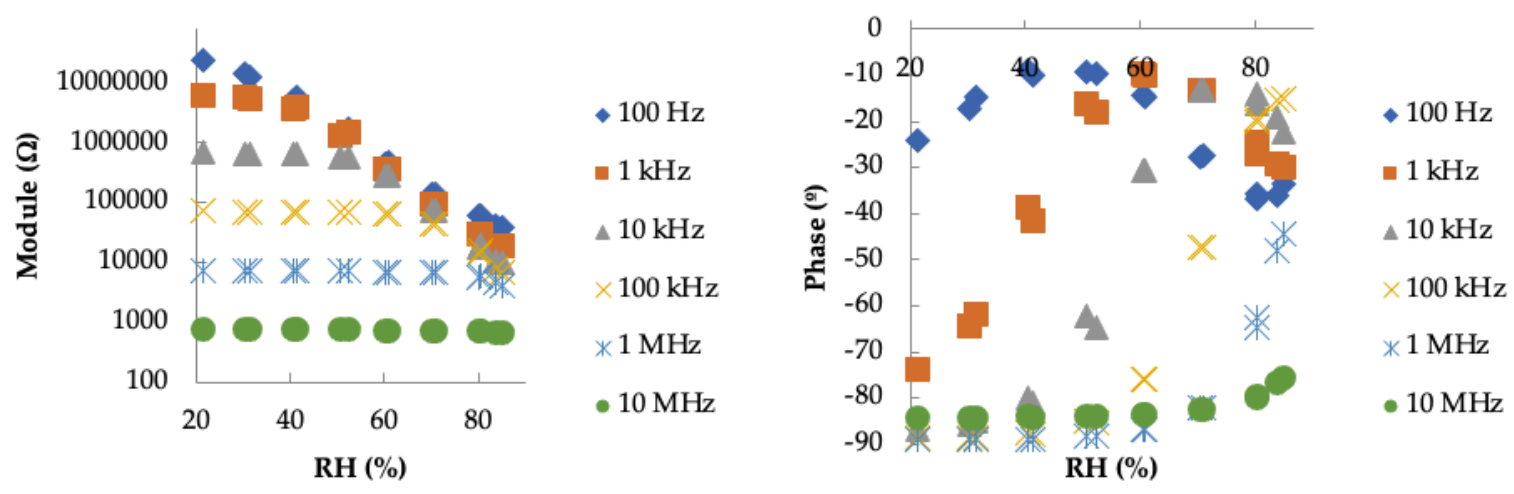

(a)

(b)
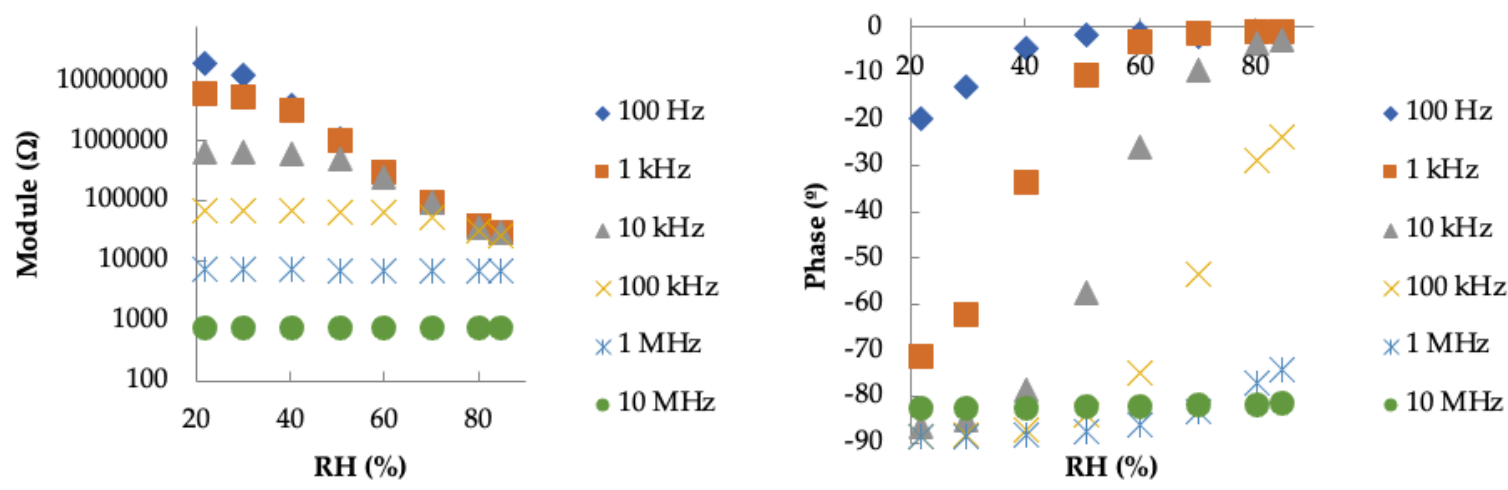

(c)

(d)

Figure S1. Impedance response towards $\mathrm{RH}$ at $40{ }^{\circ} \mathrm{C}$ and different frequencies. (a) Module and (b) Phase for substrate type 21 with Ag electrodes. (c) Module and (d) Phase for substrate type 21 with PEDOT:PSS electrodes. 

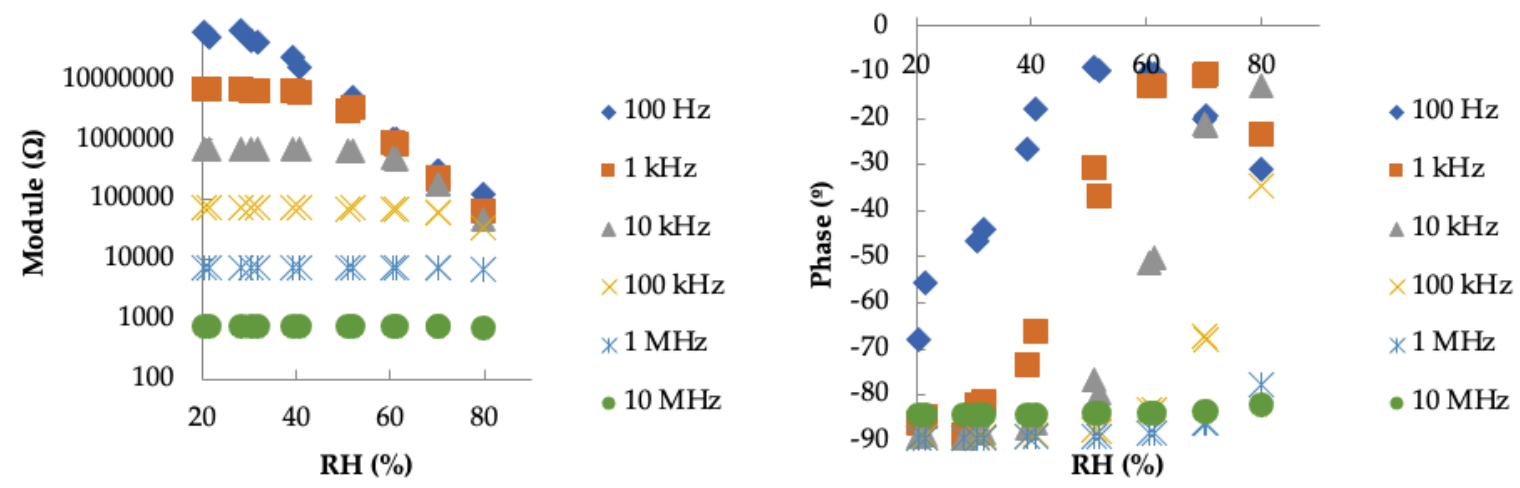

(a)

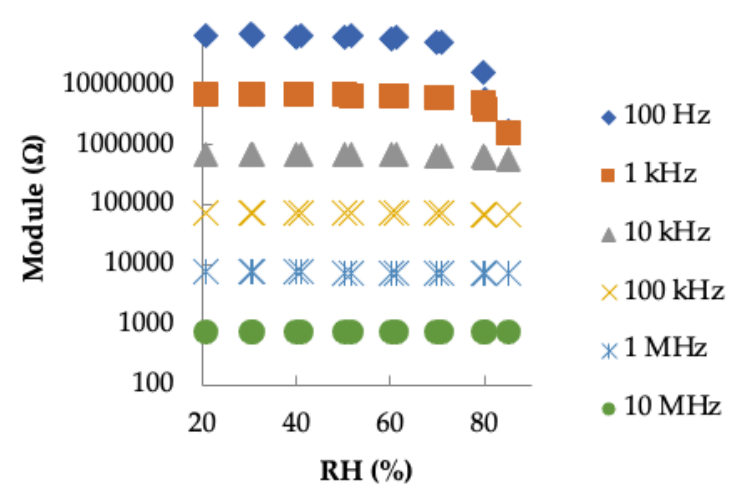

(c) (b)

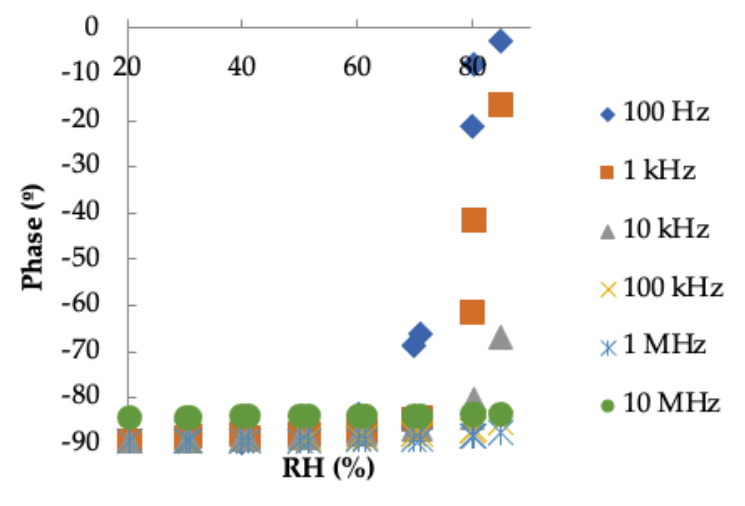

(d)

Figure S2. Impedance response towards RH at $40{ }^{\circ} \mathrm{C}$ and different frequencies. (a) Module and (b) Phase for substrate type 10 with Ag electrodes. (c) Module and (d) Phase for substrate type 10 with PEDOT:PSS electrodes.

Response to temperature

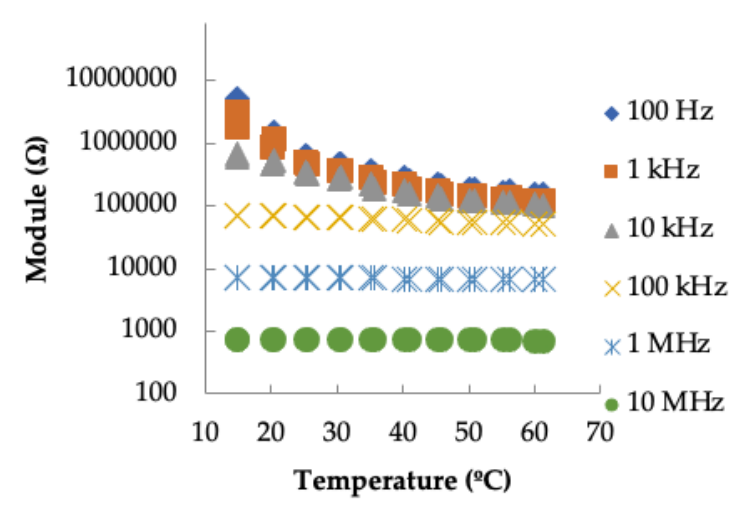

(a)

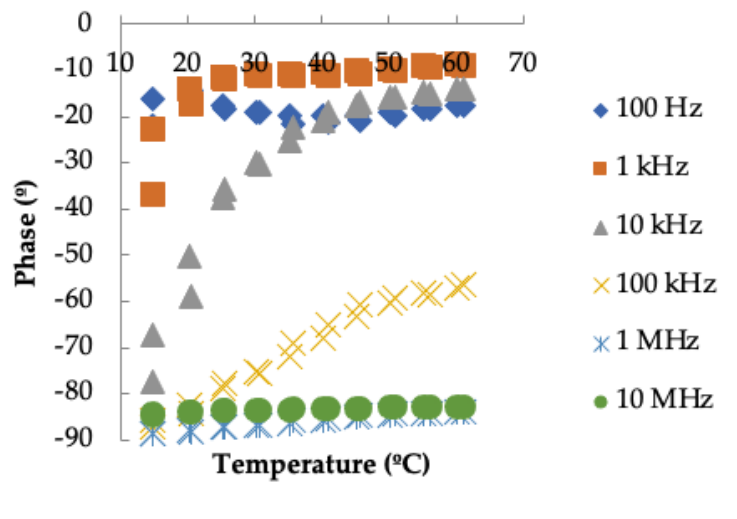

(b) 


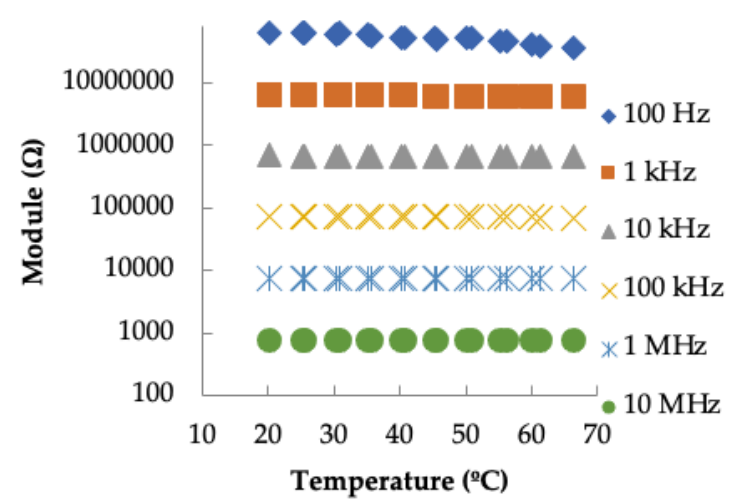

(c)

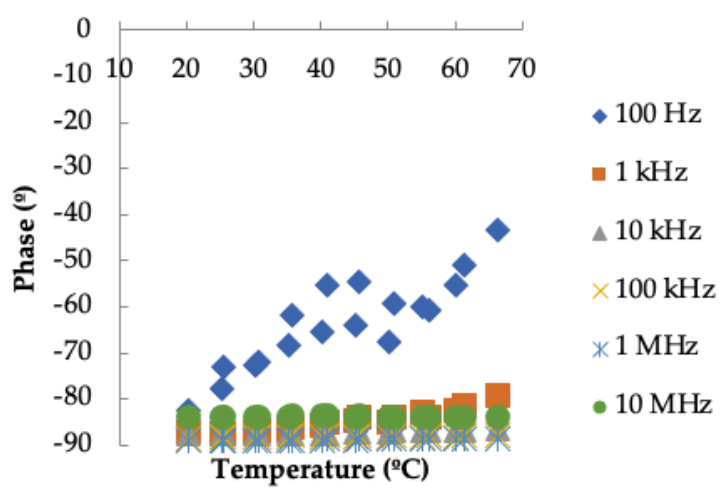

(d)

Figure S3. Impedance response towards Temperature at 55\%RH and different frequencies. (a) Module and (b) Phase for substrate type 21 with Ag electrodes. (c) Module and (d) Phase for substrate type 21 with PEDOT:PSS electrodes.

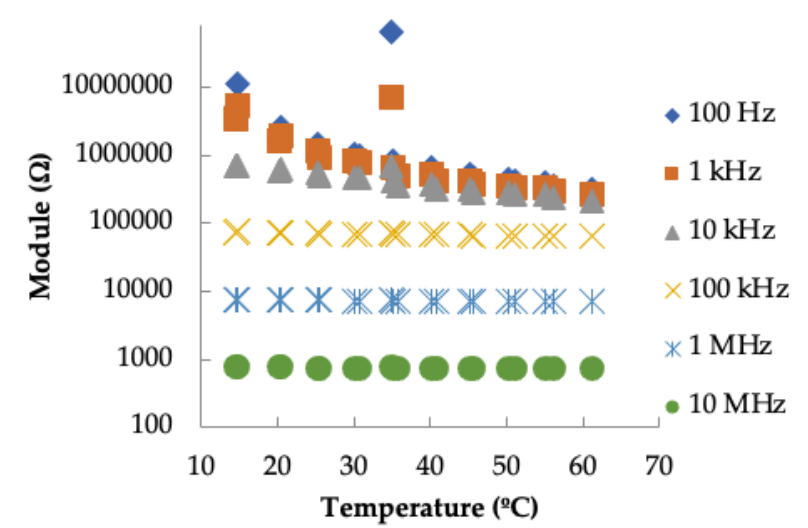

(a)

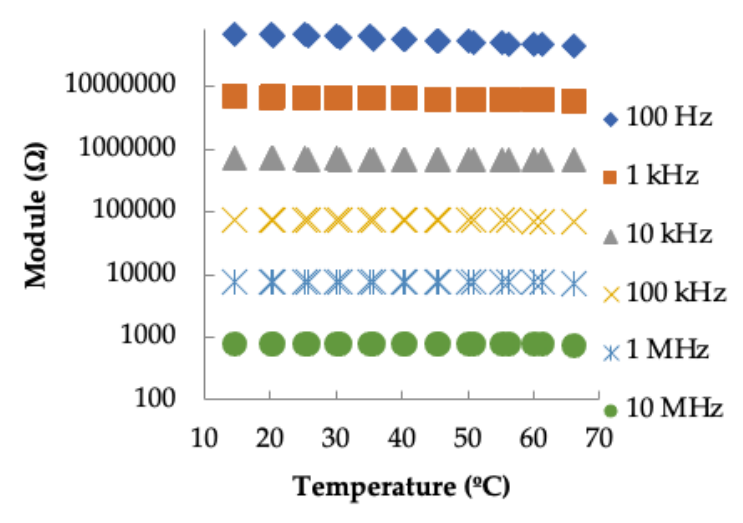

(c)

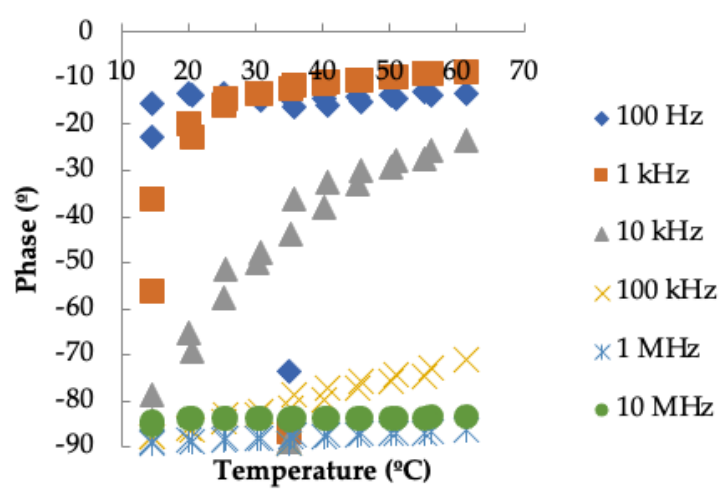

(b)

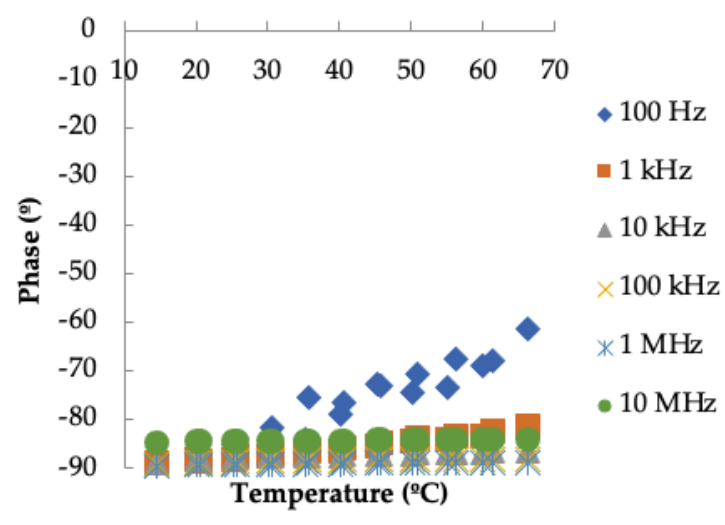

(d)

Figure S4. Impedance response towards Temperature at 55\%RH and different frequencies. (a) Module and (b) Phase for substrate type 10 with Ag electrodes. (c) Module and (d) Phase for substrate type 10 with PEDOT:PSS electrodes. 